\title{
Ishemijska kardiomiopatija
}

\section{Ana Đorđević-Dikić}

Klinika za kardiologiju, Klinički centar Srbije; Medicinski fakultet, Univerzitet u Beogradu

\section{Etiologija}

Ishemijska kardiomiopatija je oboljenje koje je karakterisano funkcionalnom slabošću srčanog mišića kao posledicom gubitka ili oštećenja srčanog tkiva (>20\%) usled akutne ili hronične ishemije. Koronarna bolest čini patofiziološki supstrat ovog obolenja, a ona je zapravo i uzrok razvoja hronične srčane insuficijencije u $70 \%$ slučajeva. U ostale uzroke se ubrajaju, valvularna bolest srca, hipertenzija i druge vrste kardiomiopatija. U razvijenim zemljama ishemična kardiomiopatija je uzrok dve trećine do tri četvrtine slučajeva dilatativne kardiomiopatije.

\section{Definicija}

Ishemijska kardiomiopatija je klinički sindrom koji se karakteriše:

Simptomima tipičnim za disfunkciju leve komore: dispneja pri opterećenju ili u miru, paroksizmalna noćna dispnea, zamor, otoci ekstremiteta.

Znacima tipičnim za disfunkciju leve komore: tahikardija, tahipneja, zastoj na plućima, pleuralni izliv, periferni edemi, hepatomegalija, povećani jugularni venski pritisak.

Objektivnim pokazateljima strukturnog i funkcionalnog oštećenja leve komore u miru: kardiomegalija, pri-

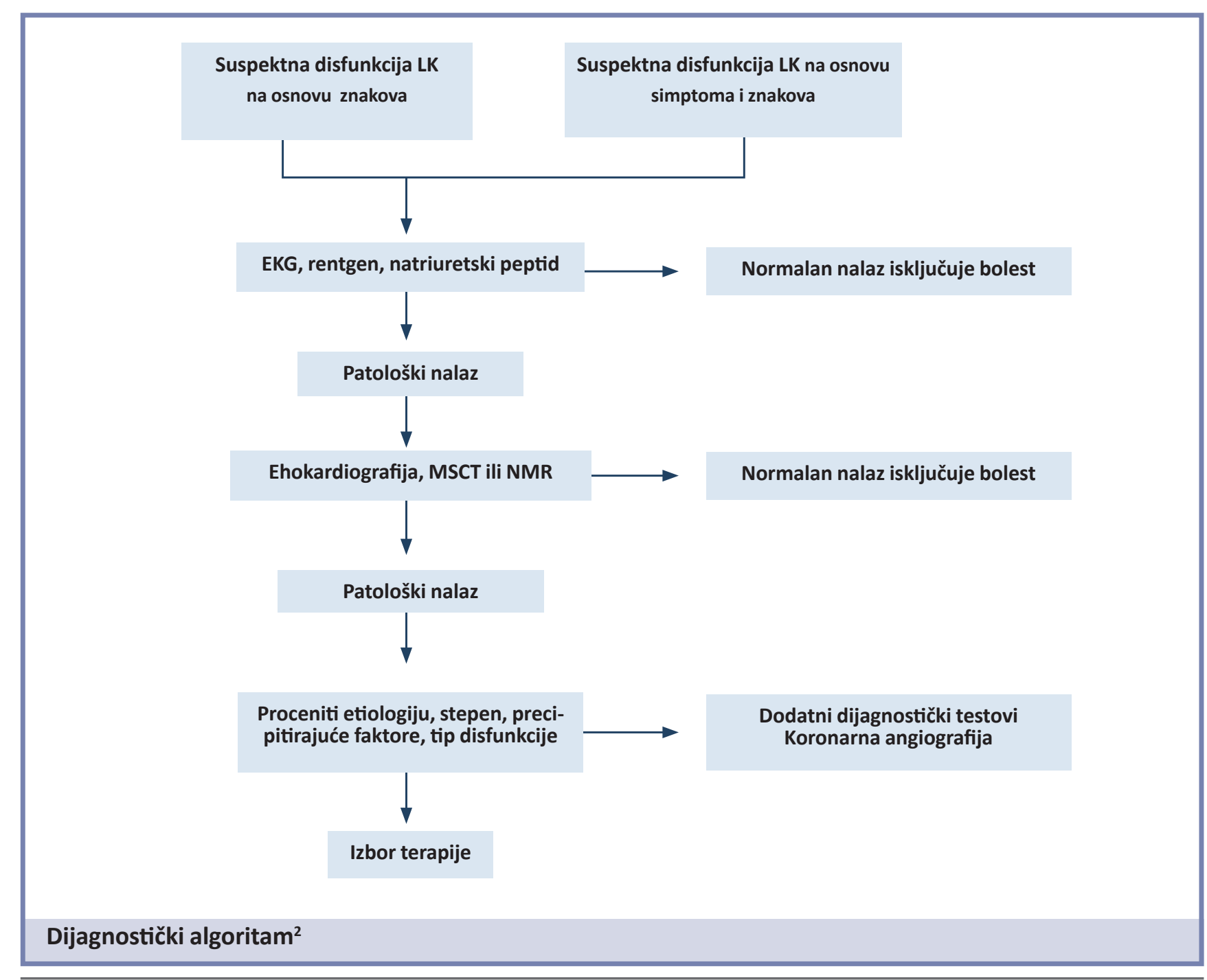

Kontakt osoba: Ana Đorđević Dikić, Klinika za kardiologiju, Klinički centar Srbije, Koste Todorovic 8, 11000 Beograd, Srbija 
sustvo trećeg tona, prisustvo šuma, promenama na ultrazvuku u smislu globalno poremećene sistolne funkcije sa smanjenom ejekcionom frakcijom (EF) i područjima poremećene kontraktilnosti i povećanom koncentracijom natriuretskog peptida. ${ }^{1}$

\section{Prognoza}

Ishemična kardiomiopatija ima lošiju prognozu u poređenju sa stabilnom anginom bez disfunkcije leve komore, kao i u odnosu na neishemijsku formu dilatativne kardiomiopatije. Razlog tome je povećani rizik od: 1) ugrožavajućih ventrikularnih aritmija, 2) pogoršanja disfunkcije komore u slučaju nove ishemije ili infarkta miokarda, 3) potencijalno fatalnih sistemskih komplikacija, 4) jatrogenih komplikacija

\section{Lečenje $^{1}$}

Osnovu lečenja čini blokada renin-angiotenzin-aldosteron sistema, koja uključuje primenu ACE inhibitora, blokatora angiotenzinskih receptora, (klasa preporuka I, nivo dokaza A) spironolaktona i aldosteronskih antagonista kod bolesnika sa nivoom kreatinina $<2.5 \mathrm{mg} / \mathrm{dL}$ i kalijumom $<5.0 \mathrm{mmol} / \mathrm{L}$ (klasa preporuka I, nivo dokaza B).

Ukoliko nisu kontraindikovani, beta blokatore treba primeniti kod svih pacijenata sa $\mathrm{EF}<40 \%$, postepeno povećavajući dozu. Potrebno je da pacijenti budu prethodno klinički stabilni (klasa preporuka I, nivo dokaza A).

Furosemid i tiazidni diuretici su indikovani kod bolesnika sa simptomima i znacima kongestije (klasa preporuka I, nivo dokaza $B$ ).

Amjodaron je lek izbora u lečenju simptomatskih supraventrikularnih i ventrikularnih aritmija $u$ ishemičnim kardiomiopatijama. Prethodno je potrebno korigovati moguće precipitirajuće uzroke aritmija i primeniti optimalne doze beta blokera, ACE inhibitora blokatora angiotenzinskih receptora i antagonista aldosterona (klasa preporuka I, nivo dokaza A).

Oralna antikoagulantna terapija je indikovana kod pacijenata sa atrijalnom fibrilacijom, ili flaterom, ili dokumentovanim trombom u levoj komori (klasa preporuka I, nivo dokaza A).
Kardioverter defibrilatori (ICD) u primarnoj prevenciji su indikovani za smanjenje mortaliteta kod bolesnika sa smanjenom funkcijom leve komore zbog prethodnog infarkta miokarda (najmanje 40 dana), EF $<35 \%$, NYHA klasa II ili III, na optimalnoj medikamentnoj terapiji i čije je očekivano preživljavanje $>1$ godinu dana (klasa preporuka I, nivo dokaza A). U sekundarnoj prevenciji ICD je indikovan kod pacijenata koji su preživeli ventrikularnu fibrilaciju i sa dokumentovanom hemodinamski nestabilnom ventikularnom tahikardijom, sa sinkopom i bez nje (klasa preporuka I, nivo dokaza A).

Kod pacijenata sa simptomatskom ishemičnom kardiomiopatijom statini smanjuju broj hospitalizacija (Klasa preporuka Ilb, nivo dokaza B).

Retrospektivne studije ili registri ukazuju da hirurška revaskularizacija miokarda produžava preživljavanje kod pacijenata sa ishemičnom kardiomiopatijom.(3) Odluku o primeni hirurške intervencije ili prekutane koronarne intervencije treba doneti na osnovu pažljive evaluacije komorbiditeta, proceduralnog rizika, koronarne anatomije, postojanja živog miokarda u regionu revaskularizacije, funkcije leve komore i prisustva značajne valvularne bolesti. ${ }^{3}$

Mogućnost regeneracije miokarda implantacijom matičnih ćelija, što treba da dovede do popravljanja funkcije leve komore, nova je nada i za pacijente i za lekare. Ova vrsta terapije je trenutno u fazi kliničkog ispitivanja, pre nego što postane deo rutinske kliničke terapije.

\section{Literatura:}

1. Dickstein K, Cohen-Solal A, Filippatos G. et al. ESC Guidelines for the diagnosis and treatment of acute and chronic heart failure 2008. The Task Force for the diagnosis and treatment of acute and chronic herat failure 2008 of the Eureopean Society of Cardiology. Developed in collaboration with the Heart Failure Association of the ESC (HFA) and endorsed by the European Society of Intensive Care Medicine (ESICM). Eur Heart J 2008; 29: 2388442.

2. Kearney M. Chronic Heart Failure. Oxford University Press, 2008: 33.

3. Shanmugan G, Legare JF. Revascularization for ischemic cardiomyopathy. Curr Opin Cardiol 2008; 23: 148-52. 